\title{
A estrutura da Ética da Compaixão de Schopenhauer em relação à Filosofia Transcendental'
}

Die Struktur der Mitleidsethik Schopenhauers in Bezug auf die Transzendentalphilosophie

The structure of Schopenhaver's ethic of compassion in terms of transcendental philosophy

\section{Yukiko Hayashi*}

Kwansei Gakuin University, Quioto, Japão; Schopenhauer-Forschungsstelle der Johannes Gutenberg-Universität Mainz, Mainz, Deutschland

\section{Resumo}

Na interpretação da ética da compaixão de Schopenhauer desenvolvida até então, a unidade metafísica entre "eu" e "outro", ou a ética do sentimento, era colocada em oposição à ética normativa kantiana. Recentemente houve novas tentativas de interpretar,

1 Traduzido do idioma alemão por Lucas Lazarini Valente.

*YH: Doutora, e-mail: sandakko1986@yahoo.co.jp 
com outra fundamentação, sua teoria do conhecimento e sua ética, a saber, com base na filosofia transcendental assumida por Kant. Com a presente reflexão, eu gostaria de contribuir com a compreensão transcendental-filosófica da compaixão na teoria da compaixão de Schopenhauer. Especialmente com recurso a dois aspectos do sofrimento na ética da compaixão, a saber, ao sentimento como afeto da vontade e à representação do sofrimento, eu esclareço que a ética da compaixão foi pensada por Schopenhauer segundo a concepção transcendental-filosófica.

Palavras-chave: Teoria do Conhecimento. Ética. Ideia. Representação. Sentimento.

\section{Zusammenfassung}

In der bisherigen Auslegung von Schopenhauers Mitleidsethik standen die metaphysische Einheit des Ich und des Anderen oder die Gefüh/sethik gegenüber der Kantischen normativen Ethik. In den letzten Jahren gab es andere, neue Versuche, seine Erkenntnislehre und die Ethik mit einer weiteren Begründung zu interpretieren: nämlich mit der von Kant übernommenen Transzendentalphilosophie. Ich möchte mit dieser Überlegung zum transzendentalphilosophischen Verständnis des Mitleids in Schopenhauers Mitleidslehre einen Beitrag leisten. Besonderes anhand zweier Aspekte des Leids in der Mitleidsethik, nämlich des Gefühls als Affekt des Willens und der Vorstellung des Leids, erläutere ich, dass die Mitleidsethik nach dem transzendentalphilosophischen Konzept von Schopenhauer gedacht wurde.

Stichwörter: Erkenntnislehre. Ethik. Idee. Vorstellung. Gefühl.

\section{Abstract}

In the interpretation of Schopenhauer's compassion ethic so far, the metaphysical unity of "I" and of "the other", or "ethic of feeling" stood in contrast to the Kantian normative ethics. Recently there have been other, new attempts to interpret his epistemology and ethics based on an additional rationale: namely, the transcendental philosophy adopted by Kant. I would like to contribute to this reflection on the transcendental-philosophical understanding of Schopenhauer's compassion. In particular on the basis of two aspects of suffering in ethics of compassion, namely, the feeling as an affect of the will and the representation of 
suffering, I explain that the ethic of compassion was conceived according to Schopenhauer's transcendental-philosophical concept.

Keywords: Epistemology. Ethics. Ideas. Representation. Feeling.

\section{Introdução}

No estudo da ética da compaixão de Schopenhauer desenvolvido até então, a unidade metafísica entre "eu" e "outro", ou a ética do sentimento, era colocada em oposição à ética normativa kantiana. Semelhante interpretação da ética da compaixão de Schopenhauer compara esta última com a teoria do conhecimento do filósofo, na qual a vontade como coisa em si, como uma substância transcendente que se encontra por detrás do mundo, atua como fundamento do mundo como representação. Isso é comum, visto que Schopenhauer diz que sua ética surgiria da mesma fonte da qual surgem outros domínios filosóficos (filosofia da natureza, teoria do conhecimento e estética) em sua obra principal O Mundo como Vontade e Representação ${ }^{2}$. Recentemente, porém, houve novas tentativas de interpretar, com outra justificativa, precisamente aquela teoria do conhecimento e a ética, a saber, com base na filosofia transcendental assumida por Kant. Dois tipos de compaixão são discutidos no contexto da filosofia transcendental: (1) o da teoria da representação (ITO, 1999; 2000) e (2) da teoria da vontade (UENOYAMA, 2008; 2011).

Se tentamos interpretar a ética da compaixão de Schopenhauer de modo que ela fique consistente consigo mesma e livre de contradições, dois níveis distintos são necessários: um nível empírico e um

2 "A tarefa da filosofia é interpretar e explicitar o existente, a essência do mundo — que se expressa de maneira compreensível in concreto, isto é, como sentimento, a cada um — e trazê-la ao conhecimento distinto e abstrato da razão, em todas as suas relações possíveis e em todos os pontos de vista. Assim como nos três livros precedentes procuramos levar isso a bom termo sob a universalidade do conceito e de diferentes pontos de vista; agora, no presente livro, a ação humana será considerada da mesma forma" (SCHOPENHAUER, 1988a, p. 320 [Trad. cit.: SCHOPENHAUER, 2015a, p. 314]). 
transcendental-filosófico ${ }^{3}$. No nível transcendental, pergunta-se pela possibilidade da experiência. No nível empírico, esse nível transcendental é já pressuposto. No nível transcendental-filosófico pode-se compreender, a partir da fórmula geral da consciência, a correlação que o "eu" e o "outro" possuem entre $\mathrm{si}^{4}$.

\section{Sobre 0 conceito de Ideia}

Na consideração do "eu" e do "outro", a Ideia platônica desempenha um papel importante, porque com ela podemos reconhecer o "eu" e o "outro", de certa forma, como cópias individuais da mesma Ideia (espécie) de humanidade. Isso vale também para a intuição espacial do eu que sofre e do "outro", por exemplo, por meio da representação do rosto de um "outro". De acordo com Schopenhauer, a Ideia platônica não é um ente metafísico-transcendente, mas um produto da atuação em conjunto da razão e da imaginação (fantasia) . $^{5}$ A diferença empírica entre o "eu" e o "outro" precisa da Ideia platônica, que é chamada de "objetidade adequada da vontade" (SCHOPENHAUER, 1988a, p. 211), porque a vontade transcendental, como espontaneidade, contribui para a existência da Ideia platônica como produto da imaginação (phantasma) ${ }^{6}$. Quando se leva em consideração a Dissertação de Schopenhauer, a Ideia platônica tem a função transcendental de garantir a identidade do objeto individual espacial, identidade que, no mundo da representação, é possível por intermédio do objeto imediato (corpo). Com essa função da Ideia platônica na teoria do conhecimento

\footnotetext{
3 De acordo com Kamata (1988, p. 203, 240 e 289), as diferentes compreensões da vontade têm sua origem nesses dois níveis. 4 Comparar com HAYASHI, 2015. Em relação à Ideia platônica como a condição espacial do sofrimento, ver ITO (1999, 2000).

5 Ver SCHOPENHAUER, 1988a, p. 48 e 1988d, p. 52. Essa razão, entendida aqui como a faculdade da universalidade (a faculdade do princípio), não é uma razão que, no nível empírico, como razão instrumental, produz conceitos a serviço da vontade individual, mas sim a condição transcendental de possibilidade do mundo como representação, ao qual pertencem as leis de homogeneidade e especificação (ver SCHOPENHAUER, 1988d, p. 3 et seq.). A imaginação é entendida, de forma transcendental-filosófica, como atuação espontânea da vontade sobre 0 conhecimento. Quanto à interpretação da Ideia platônica como phantasma (produto da imaginação), ver KAMATA, 1988, p. 166-171, p. 178-187.

6 Ver SCHOPENHAUER, 1988a, p. 48. A respeito disso ver também KAMATA, 2015, p. 53.
} 
de Schopenhauer, a compaixão é possível. Assim, a teoria da compaixão e a teoria do conhecimento possuem a mesma estrutura.

Além disso, dever-se ia ainda questionar como é vista a relação entre a Ideia platônica e o próprio sofrimento. Se a Ideia platônica fosse pensada como a Ideia espacial ou como intuição-normal, a ética da compaixão estaria sempre situada em um âmbito de problemas relacionados ao espaço. "O sofrimento" estaria ligado às representações determinadas e concretas, como as expressões faciais, e seria, nessa medida, igual a todas as outras representações (aos objetos imediatos). Mas se "o sofrimento" é vivenciado como afeto da vontade, então ele é sentido sob a temporalidade do sentido interno. Claramente, o afeto recebido através do corpo como objeto imediato pode ser conectado com a representação espacial do sofrimento. Mas esse mesmo afeto não pode ser visto espacialmente. Ele pode ser apenas sentido, com auxílio da Ideia musical ${ }^{7}$, no sentido interno. Eu chamo a forma interna, temporal, de "Ideia musical (temporal)", em oposição à forma geral espacial, à "Ideia platônica (espacial)".

Mas aqui existem outros problemas, visto que a Ideia é pensada fora de temporalidade e de espacialidade. Devemos refletir ainda uma vez a respeito do significado da Ideia.

[...] juntamente com o princípio de razão, foram suprimidos tanto a coisa individual quanto o indivíduo que conhece, restando somente a Ideia e o puro sujeito do conhecer, os quais, juntos, constituem a objetidade adequada da vontade neste grau. E a Ideia não está isenta apenas do tempo, mas também do espaço: ela não é propriamente uma figura espacial que oscila diante de mim; ao contrário, é a expressão, a significação pura, o ser mais íntimo dessa figura, que se desvela e fala para mim; Ideia que pode ser integralmente a mesma, apesar da grande diversidade de relações espaciais da figura (SCHOPENHAUER, 1988a, p. 247 [trad. cit.: SCHOPENHAUER, 2015a, p. 243]).

Da forma como Schopenhauer descreve acima a Ideia, ela não possuiria nenhuma forma imaginável; não possuiria, portanto, uma forma espacial individual, apenas a expressão, a significação pura da Ideia, sua

7 A respeito da designação da "Ideia musical", ver HAYASHI, 2016, p. 212. 
essência íntima, que se abre para mim e se dirige a mim. A Ideia é independente de tempo e espaço sob o princípio de razão, sob o qual as coisas podem se modificar. Apesar disso, a Ideia pode, de acordo com Schopenhauer, exibir o significado ou a essência íntima da própria espacialidade. A essência da espacialidade é universal. Nesse sentido, a Ideia é o ponto de revelação da própria espacialidade. Por meio da Ideia, a própria espacialidade ou a temporalidade se nos tornam visíveis. Por isso, a Ideia platônica é a própria espacialidade (e a Ideia musical é a temporalidade). No restante desse artigo, utilizo "a Ideia" nesse sentido.

Em relação ao sofrimento, explicar a Ideia platônica como uma determinação espacial não é algo pouco exigente, visto que o sofrimento é um afeto da vontade, a qual é determinada na temporalidade através do sentido interno. Sob esse ponto de vista, nossa investigação explicaria "a forma geral do afeto (ou do sentimento) da vontade" como Ideia musical, a qual desempenha um papel importante na ética da compaixão8.

Mas não ficaria claro de que forma as duas condições - a temporal e a espacial - se conectariam entre si (ou não se conectariam). Schopenhauer diz que as Ideias platônicas "não seriam válidas apenas para o formal, como é o caso com as Ideias matemáticas, mas também para o material da representação completa" ${ }^{\prime \prime}$. Por isso, permanece aqui uma questão, qual seja, se é a Ideia platônica que sustenta a Ideia musical ou se, ao contrário, é a Ideia musical que sustenta a Ideia platônica. Para esclarecer esse problema, eu gostaria de, em primeiro lugar, concentrar-me na relação entre sentimento e representação no fenômeno da compaixão e, com essa reflexão, oferecer uma contribuição para a compreensão transcendental-filosófica desse fenômeno.

8 Ver HAYASHI, 2016.

9 "As Ideias platônicas talvez possam ser descritas como intuições normais, as quais não seriam válidas apenas para o formal, como é o caso com as Ideias matemáticas, mas também para o material da representação completa: representações completas, portanto, que, como tais, seriam completamente determinadas e, no entanto, ao mesmo tempo, da mesma forma que os conceitos, compreenderiam muitas coisas em si; isto é, de acordo com minha explicação oferecida na §29, as Ideias platônicas seriam representantes dos conceitos, mas que lhes seriam inteiramente adequados"'(SCHOPENHAUER, 1988d, p. 63). 


\section{0 sentimento e a representação na ética da compaixão de Schopenhauer}

No contexto da ética da compaixão, Schopenhauer diz o seguinte a respeito do choro:

Quando nos comovemos e choramos não por sofrimentos próprios, mas alheios, isso ocorre devido ao fato de na fantasia nos colocarmos vivamente no lugar do sofredor, ou, também, mirarmos em seu destino a sorte de toda a humanidade, consequentemente antes de tudo a nossa; portanto, por um longo desvio, sempre choramos de novo por nós mesmos, somos nosso próprio objeto de compaixão (SCHOPENHAUER, 1988a, p. 445 [trad. cit.: SCHOPENHAUER, 2015a, p. 438]).

Nessa situação, a representação do outro funciona como mobilizador do próprio sofrimento ${ }^{10}$. Mas, no fim da citação, Schopenhauer diz que "por um longo desvio" choramos por nós mesmos e sentimos compaixão para conosco. Chorar por causa de nós mesmos soa um tanto quanto egoísta. Schopenhauer prossegue e considera que, visto que para a pessoa individual esse egoísmo está claramente no mundo empírico, o genuíno valor moral tem sua origem na ausência do egoísmo (SCHOPENHAUER, 1988c, p. 208). Isso deve ser mantido em mente.

Na ética da compaixão de Schopenhauer, a reflexão auxiliada pela razão deve ser rejeitada, visto que a razão no mundo empírico é uma ferramenta da vontade dialética ${ }^{11}$. Nesse sentido, a compaixão não é um fim da doutrina ética. Como julga Schopenhauer, a filosofia poderia (assim como a doutrina ética) apenas explicar "o que é", motivo pelo qual na ética de Schopenhauer não há qualquer prescrição. Com essa consideração, "esse longo caminho" não pode ser visto aqui como reflexão racional, mas sim como um processo mediado pela função da fantasia no próprio sujeito. Nós podemos encontrar essa função também em outra citação.

10 Ito (1999) também escreve a respeito da função da representação do sofrimento como motivação.

11 Ver KAMATA, 1988, p. 203: "Schopenhauer compreende esse não-querer-viver como a tarefa da vontade dialética, a qual, por meio da determinação de fins e da realização destes, constantemente produz na consciência essa discrepância entre 0 sujeito e o objeto do querer". 
Do meu ponto de vista, inclusive, nunca se chora imediatamente em virtude de uma dor sentida, mas somente devido à sua repetição na reflexão. [...] O choro é, por conseguinte, compaixão consigo mesmo ou a compaixão que retorna ao seu ponto de partida. É, pois, condicionado tanto pela capacidade de amar e de compadecer-se quanto pela fantasia (SCHOPENHAUER, 1988a, p. 444 [trad. cit.: SCHOPENHAUER, 2015a, p. 437]).

Aqui Schopenhauer menciona que o choro é a compaixão retornada ao seu ponto de partida. E que esse processo seria condicionado por meio da capacidade de amar e de compadecer-se e também por meio da fantasia. Como eu disse acima, esse processo não deve ser explicado no nível empírico, mas sim no nível transcendental. Na próxima seção, "Espontaneidade e repetição do sentimento", eu tento explicar esse processo da compaixão relacionando-o com a dissertação de Schopenhauer, para interpretar sua ética da compaixão de forma inequívoca em conjunto com sua teoria (transcendental) do conhecimento.

\section{Espontaneidade e repetição do sentimento}

Em sua dissertação, Schopenhauer considera que todos os objetos, em função de seu tipo, são divididos em quatro classes. O sentimento pertence à quarta classe de objetos para o sujeito: "Nossos sentimentos, afetos, paixões, etc., uma vez que são percebidos por nós, são sem dúvida objetos para o sujeito e devem, como tais, ou ser compreendidos no interior das classes já apresentadas, ou constituir uma classe própria" (SCHOPENHAUER, 1988d, p. 82). Apenas nessa classe os objetos existem como objetos internos, isto é, objetos enquanto sujeito do querer. Aqui domina a lei de motivação e, por isso, também o sentimento segue essa lei (p. 83). Aliás, Schopenhauer fala no mesmo capítulo sobre os phantasmata, que também são determinados pela lei de motivação. $\mathrm{O}$ sentimento não deve ser pensado como 
um phantasma, visto que esses phantasmata são meras representações ${ }^{12}$ : “Representações completas, sejam elas intuídas por intermediação do objeto imediato, isto é, sejam elas objetos reais, ou repetições evocadas por espontaneidade, isto é, phantasmata, permanecem sendo sempre representações individuais" (SCHOPENHAUER, 1988d, p. 50).

Essas propriedades dos phantasmata, no entanto, são iguais àquelas do sentimento. A respeito de "espontaneidade" e "repetição", por exemplo, podemos encontrar a proposição sobre o choro, como vimos na seção anterior: “[...] portanto, por um longo desvio, sempre choramos de novo por nós mesmos, somos nosso próprio objeto de compaixão" (SCHOPENHAUER, 1988a, p. 445 [trad. cit.: SCHOPENHAUER, 2015a, p. 437]).

Do meu ponto de vista, inclusive, nunca se chora imediatamente em virtude de uma dor sentida, mas somente devido à sua repetição na reflexão. A pessoa passa de uma dor sentida, mesmo que ela seja corpórea, para uma mera representação da mesma, e acha então o próprio estado tão digno de compaixão [...] (SCHOPENHAUER, 1988a, p. 444 [trad. cit.: SCHOPENHAUER, 2015a, p. 437]).

Essas repetições entre o sentimento e a representação devem ser pensadas em conjunto com a lei de homogeneidade (uma capacidade da razão transcendental) $)^{13}$.

12 Aqui eu digo que o sentimento é diferente dos phantasmata, visto que o sentimento não é uma representação completa (com temporalidade e espacialidade). Mas, como eu menciono na sequência, as propriedades do sentimento e dos phantasmata na quarta classe de objetos para o sujeito são, na verdade, quase idênticas. A Ideia platônica é "na verdade, um phantasma na presença da razão. Ela é um phantasma sobre o qual a razão imprimiu o selo de sua universalidade; um phantasma perante o qual ela diz: 'todos são dessa maneira', isto é, 'aquilo no que esse representante não é adequado ao seu conceito não é essencial'. A Ideia platônica surge, portanto, por meio da atividade conjunta da fantasia e da razão" (SCHOPENHAUER, 1985, p. 226 (manuscrito de 1814)). Como eu mostrei em outro artigo (HAYASHI, 2016), a Ideia musical deve ser pensada pelo afeto da vontade, mesmo na presença da forma geral (na razão como capacidade do princípio, não como reflexão no nível empírico) e da imaginação. E, de acordo com Schopenhauer, o sentimento também é um objeto e é determinado pela motivação. Nesse sentido, o sentimento funciona quase como o phantasma e, no caso do sentimento, é apenas a espacialidade que falta.

13 Ver SCHOPENHAUER, 1988d, p. 3. 
Toda figura que se apresenta repentinamente à nossa fantasia e também todo juízo que não se segue à sua razão previamente presente devem ser evocados por meio de um ato da vontade, o qual possui um motivo, apesar de este frequentemente não ser percebido - porque ele é discreto, e o ato da vontade, porque sua realização é muito fácil, acontece simultaneamente em relação ao motivo. O motivo para a evocação de semelhantes phantasmata ou também de juízos que, como se diz, nos ocorrem de repente, é geralmente a associação de ideias, isto é, o desejo, por ocasião de toda representação presente, de possuir outras semelhantes a ela. Esse ato da vontade surge do anseio de perfazer nosso conhecimento, anseio que nos é peculiar e que atua como motivo para aquele ato da vontade (por isso também este é mais forte em homens engenhosos). Em vista desse fim, é bom que representações semelhantes sejam unidas, para que, então, a lei de homogeneidade seja satisfeita (SCHOPENHAUER, 1988d, p. 80).

Essas repetições, por causa da imaginação, não são repetições normais. Os phantasmata realmente surgem de novo todas as vezes ${ }^{14}$. Essa repetição não apenas funciona como uma ponte entre o objeto interno e o externo, mas também reforça a própria relação entre os dois. Schopenhauer chama essa capacidade de memória ou capacidade exercitada $^{15}$. Conectar uma coisa com outra de acordo com a lei de homogeneidade é o que recebe o nome de associação de pensamentos ${ }^{16}$. Não se pode determinar arbitrariamente essa cadeia entre as representações e os sentimentos, porque ela surge através da lei de motivação, mas a influência, de acordo com Schopenhauer, permanece atuante.

Se, em outro momento, o retomamos [o objeto de interesse], dirigimo-nos a ele como a uma coisa nova, em relação à qual nos orientamos de modo novo, porém, com mais rapidez, e a impressão agradável ou adversa dele sobre a nossa vontade aparece então renovada. Entrementes, nós mesmos não retornarmos totalmente imodificados. É que, com a mescla física entre os humores e a tensão dos nervos, que mudam continuamente conforme as horas, os dias, e as estações do ano,

14 Ver SCHOPENHAUER, 1988d, p. 81.

15 Ver SCHOPENHAUER, 1988d, p. 81.

16 " [...] por conseguinte, necessita de uma ocasião que há de ser fornecida antes pela associação de pensamentos e pela motivação; ocasião essa, porém, que pode ser tanto mais remota e insignificante, quanto mais nossa suscetibilidade a ela é incrementada pelo interesse no objeto" (SCHOPENHAUER, 1988b, p. 154 [trad. cit.: SCHOPENHAUER, 2015b, p. 171]).

Rev. Filos., Aurora, Curitiba, v. 30, n. 49, p. 255-269, jan./abr. 2018 
também alteram-se a nossa disposição e perspectiva: ademais, os diferentes tipos de representação que nesse ínterim ali estiveram, deixaram um eco, cujo tom exerce influência sobre as seguintes. Por isso a mesma coisa aparece-nos amiúde bem diferente conforme diferentes tempos, manhã, tarde, meio-dia ou no outro dia. (SCHOPENHAUER, 1988b, p. 151 [trad. cit.: SCHOPENHAUER, 2015b, p. 168])

Aqui há uma maior ou menor influência da representação e do sentimento enquanto afeto da vontade. Como eu mencionei acima, o sentimento segue a lei de motivação; é por isso que, na verdade, é difícil afirmar com qual representação pode-se sentir "sofrimento", já que isso depende da personalidade do indivíduo. Mas essa combinação entre a representação e o sentimento tem efeito em uma pessoa. Por isso agora, na última seção, eu tentarei esclarecer, como for possível, de que forma esses diferentes objetos, o sentimento e a representação, podem ser conectados entre si.

\section{Antecipação do sentimento}

Com as seguintes citações, tentaremos esclarecer a relação entre o sentimento e a representação:

Aquilo que confere unidade e coesão à consciência, na medida em que, perpassando todas as suas representações, é seu substrato, seu sustentáculo permanente, não pode ser condicionado pela consciência, logo, não pode ser representação alguma: antes tem de ser o prius da consciência, a raiz da árvore da qual aquela é o fruto. Isso, eu digo, é a vontade: [...]. É ela que atribui coesão a todos os pensamentos e representações, como meios em vista de seus fins, tingindo-os com a cor de seu caráter, da sua disposição e do seu interesse, domina a atenção e manipula o fio dos motivos, cujo influxo em última instância põe em atividade também a memória e a associação de ideias (SCHOPENHAUER, 1988b, p. 153 [trad. cit.: SCHOPENHAUER, 2015b, p. 170]).

“Toda paixão, sim, toda inclinação e aversão tinge os objetos do conhecimento com sua cor" (SCHOPENHAUER, 1988b, p. 155 [trad. cit.: SCHOPENHAUER, 2015b, p. 172]). Dominar “a atenção" significa 
organizar a priori a representação. Schopenhauer diz que essa função seria a "sensibilidade", a qual varia bastante conforme a diferença entre os homens ${ }^{17}$. Com essa própria sensibilidade já classificamos as coisas, mas não somos capazes de conhecê-la. Essa sensibilidade é igual à antecipação da Ideia na estética de Schopenhauer ${ }^{18}$. Tingir os objetos do conhecimento com as cores de toda paixão, inclinação ou aversão exibe essa antecipação a priori da Ideia. Nesse sentido, a antecipação da Ideia platônica deve ser vista como a determinação da vontade interior.

Por isso, semelhante antecipação pode também ser assumida na ética, como ocorre na seguinte citação:

Segundo o que foi dito, nas ações individuais do homem justo, a compaixão atua apenas indiretamente, através dos princípios, e não tanto como "actu", mas como "potentia", do mesmo modo que, em estática, a maior velocidade causada pelo maior comprimento de um dos lados da balança, em virtude da qual a massa menor mantém o equilíbrio da maior, age no estado de repouso apenas em "potentia" tão bem quanto em "actu". Todavia a compaixão está sempre pronta para manifestar-se em "actu". Por isso, quando, de algum modo, a máxima escolhida da justiça vacila nos casos individuais, nenhum motivo (pondo-se de lado o egoísta) é mais eficaz para dar apoio à justiça e para avivar os preceitos justos do que aquele que é extraído da própria fonte originária, da compaixão (SCHOPENHAUER, 1988c, p. 214 [trad. cit.: SCHOPENHAUER, 2001, p. 145]).

O ponto mais importante é que essa antecipação não funciona de forma construtiva, mas sim de forma regulativa. É por isso que essa função é entendida como "potentia", para que nenhuma coisa transcendente tenha de ser pressuposta. A filosofia de Schopenhauer mantém-se na representação (na imanência).

A representação do sofrimento como o objeto imediato através do objeto mediato é até mesmo algo neutro na primeira classe dos objetos, de acordo com a dissertação de Schopenhauer (para o que se segue,

17 Ver SCHOPENHAUER, 1988b, p. 154.

18 "Semelhante antecipação é o ideal: é a Ideia, na medida em que esta, pelo menos em parte, é conhecida a priorie, enquanto tal, complementando o que é dado a posteriori pela natureza, torna-se prática para a arte" (SCHOPENHAUER, 1988a, p. 212 [trad. cit.: SCHOPENHAUER, 2015a, p. 257]). 
me refiro a essa representação como " $\mathrm{A}$ "). Através de " $\mathrm{A}$ " um certo movimento da vontade faz efeito com a lei de motivação. Nesse momento há apenas esse movimento na consciência, já que na consciência existe apenas um objeto para o sujeito. Esse movimento pode ser "sofrimento" (objeto " $\mathrm{B}$ ") e este pertence à quarta classe de objetos. " $\mathrm{A}$ " $\mathrm{e}$ " $\mathrm{B}$ " são conectados por meio da lei de homogeneidade. Nessa conexão, as representações são trocadas rapidamente e por influência do afeto da vontade a representação recebe uma coloração. Nesse processo transcendental entre associação de pensamentos, motivação e memória (capacidade exercitada) do sujeito que conhece, pode-se reconhecer inconscientemente uma representação como a representação que recebeu a coloração do sentimento.

\section{Considerações finais}

Nessa consideração eu esclareci a relação entre a Ideia platônica e a Ideia musical. A Ideia musical não funciona como actus, mas como potentia para a Ideia platônica, visto que na consciência existe sempre apenas um objeto. Por isso, quando o objeto, por meio do objeto imediato (corpo), se torna o objeto para o sujeito, a Ideia musical tem de, como potentia, recuar. A representação do outro como sofrimento (o sofrimento como representação) precisa dessa cooperação das duas formas distintas. Essa relação é igual à relação estabelecida entre a representação global e a representação imediatamente presente. De acordo com Schopenhauer, a presença da representação é um ser-representado, e a representação global, um poder-ser-representado (SCHOPENHAUER, 1988d, p. 24). Essa questão em torno da representação global e da representação imediatamente presente é ainda um problema controverso. Com essa discussão a respeito da ética da compaixão, a filosofia transcendental de Schopenhauer e sua teoria do conhecimento podem ser consideradas sob um novo ponto de vista. 


\section{Referências}

HAYASHI, Y. Uma consideração transcendental-filosófica da compaixão: Identidade e Diferença entre Eu e Outros [em japonês]. In: Schopenhauer-Studien, Band XX. Tóquio: Japanische Schopenhauer-Gesellschaft, 2015.

HAYASHI, Y. Schopenhauer zwischen der Transzendentalphilosophie und der Ethik: Eine Betrachtung über das Leiden und die Idee. In: Schopenhauer-Jahrbuch 97. Schopenhauer-Gesellschaft, 2016. p. 211-220.

ITO, T. A "compaixão" de Schopenhauer como filosofia transcendental [em japonês]. In: Schopenhauer-Studien, Band IV. Tóquio: Japanische Schopenhauer-Gesellschaft, 1999.

ITO, T. Vontade e Representação na Compaixão de Schopenhauer [em japonês]. In: Schopenhauer-Studien, Band V. Tóquio: Japanische SchopenhauerGesellschaft, 2000.

KAMATA, Y. Der junge Schopenhauer. Genese des Grundgedankens der Welt als Wille und Vorstellung. Freiburg/München: Alber, 1988.

KAMATA, Y. Die Kant-Rezeption des jungen Schopenhauer in Ueber die vierfache Wurzel des Satzes vom zureichenden Grunde. In: BIRNBACHER, D. (Hrsg.), Schopenhauers Wissenschaftstheorie: Der Satz vom Grund - Beiträge zur Philosophie Schopenhauers. Würzburg: Könishausen \& Neumann, 2015. p. 45-58. Band 16.

SCHOPENHAUER, A. Diefrühen Manuskripte 1804-1818.In:SCHOPENHAUER, A. Der Handschriftliche Nachlaß. Hrsg. v. Arthur Hübscher. 5 Bände in 6 . Frankfurt am Main: Verlag W. Kramer, 1966-1975. Taschenausgabe (band- u. seitengleich) München: dtv, 1985.

SCHOPENHAUER, A. Sämtliche Werke. Hrsg. v. Arthur Hübscher. 7 Bände. 4. Aufl. Mannheim: F.A. Brockhaus, 1988 (= Werke).

SCHOPENHAUER, A. Die Welt als Wille und Vorstellung I. In: Werke, volume II, 1988a.

SCHOPENHAUER, A. Die Welt als Wille und Vorstellung II. In: Werke, volume III, 1988b. 
SCHOPENHAUER, A. Die beiden Grundprobleme der Ethik. In: Werke, volume IV, 1988c.

SCHOPENHAUER, A. Ueber die vierfache Wurzel des Satzes vom zureichenden Grunde, Dissertation 1813. In: Werke, volume VII (1988d).

SCHOPENHAUER, A. Sobre o Fundamento da Moral. Tradução de Maria Lúcia M. O. Cacciola. São Paulo: Martins Fontes, 2001.

SCHOPENHAUER, A. O mundo como vontade e como representação. Tradução, apresentação, notas e índices de Jair Barboza. 2. ed. São Paulo: Editora UNESP, 2015a. Tomo I.

SCHOPENHAUER, A. O mundo como vontade e como representação. Tradução, apresentação, notas e índices de Jair Barboza. São Paulo: Editora UNESP, 2015b. Tomo II.

UENOYAMA, A. A filosofia da natureza de Schopenhauer e a ética da compaixão: a respeito da compreensão do mundo através da analogia da vontade [em japonês]. In: Science of mind, n. 46. Tokyo: Philosophisches Seminar in Nihon Universität, 2008.

UENOYAMA, A. Schopenhauer e a ética animal - o significado moderno da ética da compaixão [em japonês]. In: Risou, n. 687. Chiba: Risousya, 2011.

Recebido: 08/02/2018

Received: 02/08/2018

Aprovado: 22/02/2018

Approved: 02/22/2018 